\title{
Humanitarian Communication Through the Lens of Feminist Ethics of Care
}

\author{
Houda Houbeish \\ Faculty of Information and Media Studies \\ Western University
}

\begin{abstract}
Ethical principles are the driving force of humanitarian action; they lie at the heart of the definition of humanitarian work and shape its objectives and mission. In 1965, The "Proclamation of the Fundamental Principles of the Red Cross" instituted the seven principles that govern humanitarian action until today: humanity, impartiality, neutrality, independence, voluntary service, unity, and universality. Researchers have primarily focused on studying organizational commitment to these principles, paying less attention to the role-specific ethics of this field. Moreover, researchers who consider the humanitarian field from a media studies lens have often focused on media representation, while questions about communication as practice are sidelined. In this paper, I approach humanitarian ethics with a particular focus on role morality and communication practices. With a specific focus on the role of a humanitarian communications specialist, I argue that the feminist ethics of care is a useful framework that can guide communication specialists to better practices when they are in the field of operation. I also answer the following research questions: What are the main ethical principles that humanitarian communication specialists are expected to observe? Why are these principles insufficient? How might feminist ethics of care fill the gap left by current humanitarian principles, and what would be the added value of this framework for practicing humanitarian communication? To answer, I ground my approach in an experiential understanding built from my personal experience as a humanitarian communications specialist. Second, I offer a literature review to highlight the common ground between humanitarian ethics and the feminist ethics of care. Then, I discuss the added value of the feminist ethics of care if applied by humanitarian communication specialists. Finally, I provide some examples of communications practices that would be improved to follow the feminist ethics of care model.
\end{abstract}

\section{Keywords}

Feminist ethics of care, communications, humanitarian work. 
Ethical principles are the driving force of humanitarian action; they lie at the heart of the definition of humanitarian work and shape its objectives and mission. In 1965, The "Proclamation of the Fundamental Principles of the Red Cross" instituted the seven principles that govern humanitarian action until today: humanity, impartiality, neutrality, independence, voluntary service, unity, and universality. The first four principles have been the most widely influential in the humanitarian field (Labbé and Daudin, 2016) and thus have been considered foundational values in humanitarian action.

Existing literature shows that these universal humanitarian principles have posed some challenges to humanitarian organizations because they are not culturesensitive and very general. Due to their universal nature, each of these values has been susceptible to varying interpretations by humanitarian actors interpretations (Slim, 1997; Dijkzeul and Moke, 2005; Labbé, and Daudin, 2015), which has consequently hindered these principles' efficiency in unifying practices and morals in the humanitarian field. Moreover, there is no direct relationship between these principles and communications practices and activities, except for the principle of humanity that focuses on dignity in humanitarian communications ${ }^{1}$. Finally, these principles have also led many organizations to disregard that humanitarian workers usually come from other professions--physicians, lawyers, social workers, psychologists, photographers, and accountants-- who typically have their own ethics codes. Consequently, humanitarian workers have been expected to shift their moral reasoning from their profession-specific values to humanitarian ones; meanwhile, the prospect of combining humanitarian principles with professional codes to improve the performance of humanitarian workers has neither received investment nor investigation.

This paper is particularly interested in the role of a humanitarian communication specialist, i.e., the person or people in charge of producing the public/external content that humanitarian organizations share in various forms and through multiple platforms. Through my professional experience as a journalist and a humanitarian communication specialist, I have learned that there are many similarities between these two roles on the level of responsibilities, tasks, and educational background. Often, communication specialists have studied journalism and thus carry many of the same skill sets and approaches to storytelling. However, in an age when journalism has become known for its fast, sometimes superficial, or

${ }^{1}$ Slim (2015) mentions that "To date, humanitarians have been good at writing their ethics in declamatory principles, but the profession remains strangely under developed in exploring its applied ethics" (p.21). 
misleading and sensational approach to content creation, communication specialists-many former journalists or social media managers-are now expected to present their humanitarian organizations in an ethical and humanitarian way. In this paper, I argue that currently employed humanitarian principles are overly broad and insufficient for guiding these communications practices. I argue that, due to the rising challenges in the domain of public communication as well as the growing need for fast and saleable content in print and on social media, there should be a clear, culturally- and geographically- sensitive, and role-based ethical approach that communication specialists could use daily on their jobs. I also suggest using the feminist ethics of care as an ethical framework to guide humanitarian communications specialists. Therefore, in this paper, I answer the following research questions:

- What are the main ethical principles that humanitarian communication specialists are expected to observe? Why are these principles insufficient?

- How might feminist ethics of care fill the gap left by current humanitarian principles, and what would be the added value of this framework for practicing humanitarian communication?

\section{Background}

After a preliminary review of the feminist ethics of care literature, I realized that the main difference between humanitarian and feminist ethics of care is the world views from which each framework departs. While the humanitarian field is motivated by a human rights approach and is concerned with individual rights, the ethics of care is a responsibility-based framework that focuses on interconnectedness, relationships, and communities. The other less noticeable difference between these two frameworks is that humanitarian ethics are based on universal principles while feminist ethics of care works upon particularity. I believe, however, that there is enough common ground between the two frameworks to allow an application of the ethics of care to the humanitarian field. Moreover, both frameworks can complement each other by forming a comprehensive approach that responds to the particularities of an ethical dilemma and syncs with humanitarian principles. My argument is bolstered by Slim's (2015) work on humanitarian ethics. After years of academic and professional engagement with the humanitarian field, Slim (2015) has compiled a realistic understanding of the work dynamics in this domain and what it means to be a humanitarian. His knowledge about the humanitarian field goes a step further than academic research that lacks field experience and is limited to 
knowledge acquired through literature review and data collection methods ${ }^{2}$. Therefore, Slim's (2015) work has made me realize the value of my personal experience in the humanitarian field in producing academic knowledge. Consequently, I use this approach to answer the research questions I have raised.

\section{Method}

Influenced by the worldview I described in the previous section, I chose autoethnography as my data collection method. First, I describe my experience working as the communication officer for an international refugee non-governmental organization that assists Syrian refugees in Lebanon. I worked for this organization for two years, from 2018 to 2020, and gained office and field experience through interviewing beneficiaries, writing success and human interest stories, capturing photos during events, managing social media accounts, and budgeting visibility activities. Second, I use recollections of my work experience, including the discussions held with my managers, my work on developing a set of "Standard Operational Procedures" (SoPs) for guiding an ethical and organized performance in my position, and the lessons I learned to create a list of examples on how the feminist ethics of care might be practiced in the field. I provide these examples while I am aware of the "irreducible particularity" 3 of the feminist ethics of care model, which opposes the reliance on universal principles or best practices. So, I do not claim that the examples apply to all or any situation, but I use them as tangible evidence of the usefulness of this feminist approach. Finally, my six years of professional experience in journalism and academic training in journalism are underlying my understanding of ethics in public communication.

To credibly implement the method of auto-ethnography, the researcher needs to be reflective about their involvement (Wall, 2008) because this kind of ethnographic work aims at observing oneself instead of others. Moreover, the added value of auto-ethnography is that it challenges mainstream research methods in social sciences that usually offer researchers a privileged position from which to gaze at other individuals or communities.

Using ethnography to understand the humanitarian field may fill some persistent gaps in the literature. For example, Ong (2019) argues that applying ethnog-

2 Slim (2015) acknowledges his biases by mentioned that he had "studied theology at university and write as a European Christian with liberal political opinions. [His] intellectual tradition is confined to the canons of Western thought, with its classical and Judeo-Christian origins. [He is] largely ignorant of other traditions of human thought and feeling" (p.21).

${ }^{3}$ A particularity of the agent, the other, and the situation" (Blum, 1988, p. 475). 
raphy for studying humanitarian communication "can offer sharper critique of media and technological harm" (p.481). Applying this methodology is also a way to answer research questions that focus on communications practices, which is an area that continues to be under-researcher (Orgad, 2018). Moreover, the literature also shows that researchers who use their personal experience to study the humanitarian field, such as Bell and Carens (2004) and Sommers-Flanagan (2007), built their analyses on a solid understanding of the humanitarian field. They thus contributed realistic recommendations and solutions for problems. In this way, my data collection method also fills gaps in the literature because it relies on firsthand knowledge and thus leads to authentic findings.

However, because I rely on my professional experience, my research is susceptible to inquirer's "bias" (Creswell and Creswell, 2018, p. 258), which may be particularly embodied in my examples of practices that are an exercise of feminist ethics of care. I try to overcome this challenge by merging and comparing my personal experiences with the literature review on the most salient ethical practices in the domain of public communication, particularly in the field of journalism. I mainly relied on Quintanilla, et al.'s (2014) report entitled “Reporting on Humanitarian Crises: A Manual for Trainers \& Journalists and an Introduction for Humanitarian Workers" as a tangible example of what good public commination practices in the context of a crisis looks like. However, future research on this topic might build on the work done in this paper by interviewing communications specialists who work at different organizations and in different locations to discuss their understanding of humanitarian ethics and the usefulness of ethics of care to the job.

\section{Feminist Ethics of Care: From Personal Experience to Academia}

It was challenging for me to get a job in the humanitarian field in Lebanon without prior experience as a humanitarian. I had, therefore, to prove my merit by highlighting my various professional experiences, skills, and knowledge through an exam and an interview. In addition to holding a Bachelor's degree in communications arts with an emphasis on journalism as an undergraduate, I also held a Master's degree in Media Studies when I applied for the job. On the professional level, I had six years of journalism experience and three years of experience in advocacy and public communications with a local advocacy group in my city. I dedicated my Master's thesis to studying the communication tactics of advocacy collectives in Lebanon, a relevant area to the job. However, if there was one question-- and one right answer-- that made me earn the position of a national communications officer, it would be the question posed by the advocacy specialist who was interviewing me next to the human resources specialist. She presented a hypothetical ethical dilem- 
ma that required me to make a moral decision in few seconds. The scenario was the following: "What would you do if you had a tight deadline to report a story to a donor and after receiving informed consent from the participant and interviewing her she called on the date of the deadline saying that she would like to withdraw her consent?". After a few seconds of thinking, I said that I would cancel the story. The interviewer reminded me that I would miss the deadline. I assured her that I would cancel the story. She could not help but smile.

\section{The Feminist Ethics of Care: A Definition}

The idea of feminist ethics of care originated with Carol Gilligan's (1982) book In a Different Voice. From a psychological approach, she uses evidence from interviews with young women about their abortion decisions to make sense of the process of moral reasoning that women undergo and the considerations that these decisions entail. In her book, Gilligan (1982) argued that women tend to use what she calls the "ethics of care" as a moral framework when faced by an ethical dilemma. Gilligan (1982) believed that women usually see themselves and other people, as connected one to the next, in webs of responsibility. Her work emerged in response to her mentor Lawrence Kohlberg (1981) who claimed that men are superior moral beings, and denied the capacity of women to make moral decisions. Gilligan's work also challenged the dominant Enlightenment moral theories ${ }^{4}$ that encouraged individualism and created the rational/emotional dichotomy (Lindemann, 2019).

While the Enlightenment theories that primarily influence the AngloAmerican culture and morality have been developed by men and believed that $b$ white heterosexual man was the standard and superior form of humanity, Gilligan challenged mainstream approaches in psychology the by drawing her theory on interviews with women. Gilligan's theory of ethics appreciated the particularities of a moral dilemma; Enlightenment theories, on the other hand, relied on "hypothetical dilemmas" (Gilligan, 1982, p.69), which they assumed would apply to different circumstances. Kantianism, for example, "allows no exceptions to perfect duties" (Quinn, 2014, p.72); because lying is immoral, then people should always avoid lying no matter who might be hurt if the truth was out. This logic does not acknowledge the particularity of the relation that might connect the moral agent and the other person involved in the situation that require lying. Furthermore, Enlightenment theories assumed that rationality is exclusive of emotions and believed that women

\footnotetext{
4 The Enlightenment theories with their impartialist approach to morality have been the dominant moral approaches in "Anglo-American moral philosophy" (Blum, 1988, p. 472).
} 
"lack full moral agency" (Clement, 2019, p.3). The rational/emotional dichotomy, in addition to being "misogynistic," misrepresents "emotions and its relationship to reason" (Clement, 2013, p.1931). I challenge this dichotomy by highlighting the importance of emotions in moral decision-making. I am also not arguing that care and emotionality are traits of "women" as a gender, instead, my goal is to abolish the stereotypical dichotomy that claims that only women are capable of being emotional and only men are capable of being rational. My goal in this paper is to normalize acknowledging emotions, relationships, and responsibility as factors that impact resolving ethical dilemmas and decision-making for every person. I believe that individuals and institutions should adopt an ethics of care for our communities to become more just and accommodating environments. Furthermore, this paper contributes to feminist efforts to re-categorize emotions and relationships, from being considered personal to becoming public and from being considered intimate to political.

I choose the feminist ethics of care as an alternative framework to morality in the humanitarian field because it "values emotion rather than reject it" (p.10). Held (2006) mentions that according to the feminist ethics of care, "emotions as sympathy, empathy, sensitivity, and responsiveness are seen as the kind of moral emotions that need to be cultivated not only to help in the implementation of the dictates of reason but to better ascertain what morality recommends" (Held, 2006, p.10). This theory acknowledges the added value of emotions for "Understanding the needs, interests, and welfare of the other person, and understanding the relationship between oneself and that other" (Blum, 1988, p.475). The ethics of care encourages viewing the other as an autonomous and self-sufficient human and "as different in important ways from oneself, as a being existing in her own right, rather than viewing her through a simple projection of what one would feel if one were in her situation" (Blum, 1988, p.475). This view contradicts the mainstream definition of empathy that calls for putting oneself in another person's shoes. Moreover, feminist ethics focuses on "responsibility and relationships" rather than "rights and rules" or "equality and reciprocity" (Gilligan, 1982, p.73). This theory suggests that moral decisions should always acknowledge our responsibility towards oneself and others, or put differently, our responsibility to a community where we are all connected through "webs of responsibilities" (Caswell \& Marika, 2016, p.28); it thus calls for an inclusive social setting that does not exclude anyone, even those who violate the social rules, through "restorative models that aim to reintegrate violators into communities and to re-establish mutually responsive relationships" (Caswell \& Marika, 2016, p.29). Moreover, the feminist ethics of care approaches ethical dilemmas by acknowledging the "particularity of the agent, the other, and the situation" (p.475). In other words, the feminist ethics of care emphasizes the importance of situating an 
ethical dilemma in a real and particular context because details can influence decision making; it allows for recognizing "situational demands" that can obstruct what is referred to, in liberal discourses as "individual choice and free will" (Caswell \& Marika, 2016, p.28). While some women have been taught that the care for others requires an "ethic of self-sacrifice," Gilligan's (1982, p.132) analysis of some interviews with young girls who were trying to solve the abortion dilemma shows that these girls were not able to adopt the approach unless they first were able to care for themselves. By setting the foundation of the ethics of care, Gilligan contested her contemporaries' approaches to morality by acknowledging the usefulness of emotions such as care, empathy, and responsibility in shaping moral decisions. Gilligan's theory has been considered a feminist theory of ethics because it was based on studying women while her predecessors, including Kohlberg, excluded women from their studies. While Gilligan's theory has been criticized for re-producing the social role and image of women as caregivers and as agents who are always expected to sacrifice their needs and wants for dependents, Gilligan' (1982) makes it clear that self care and autonomy are the pre-requisites of proper moral reasoning and care for others.

To sum up, Gilligan (1982) suggests that acting upon the ethics of care requires the following: (1) "a progressively more adequate understanding of the psychology of human relationships;" (2) "an increasing differentiation of self and other;" and (3) "a growing comprehension of the dynamics of social interaction" (Gilligan, 1982, p.74). Lindeman (2019) also provides some guidance to applying this theory, which reflects the worldview of feminist ethics: "If you care about the person you are caring for, you interact with [them] not simply as an object of your care but as someone with wants, intentions, and desires of [their] own" (p.108). Nevertheless, applying the feminist ethics of care is challenging because it is based on a personal understanding of care, emotions, and responsibility. It thus requires continuous reflection on a person's intentions, behavior, and the consequences caused by their behavior.

\section{Humanitarian Communication as a Professional Field}

As a communications officer, I was supervised by the grants' specialist and then the advocacy specialist, a form of line management common among humanitarian organizations. Some organizations have an independent communications department that still has to coordinate with grants and advocacy specialists. Most humanitarian organizations approach communications as a tool to comply with donors' requirements, fulfill the organization's fundraising ambitions, or disseminate political messages. Therefore, as a communications specialist, I often faced ethical 
dilemmas where I had to prioritize the benefits of one of the following stakeholders-who enjoy varying levels of power-- over others: (1) the donors who fund the communications activities as part of their grant to the organization and whose relationship with the communications' department is usually centered on implementing communications activities that highlight the contribution of the donor to the recipients of assistance. Donors' aim is usually to make their contributions visible as part of their public relations strategy, (2) the organization itself, which is in best cases interested in creating a coherent image or "brand" for itself to attract more donors and create awareness among the public around the assistance it provides; organization are usually interested in meeting the donors' visibility requirements, and (3) the beneficiaries of assistance -- usually from vulnerable populations.

This structure, which always situated communication activities as tools for fund-raising or political activity, had limited my capacity to write stories that challenged mainstream narratives about the community; It also hindered my ability to brainstorm or implement communications activities that responded to the needs and concerns of the beneficiaries of assistance. Consequently, following the universal humanitarian protocols was never sufficient for guiding me into doing the right thing. I visited the field once to collect a success story about an adolescent girl who went back to school with support from the organization for which I worked. After interviewing the 13-year-old refugee girl Rym (pseudonym) 5 to showcase her story on the organization's Facebook page, it was time to photograph her. Although I received Rym's consent, in addition to the consent of her parents, for both the interview and the photo session, she seemed reluctant. I suggested trying a few shots before starting the "official" photo session to check out how she would look on the camera. She liked the photos and asked me about who was going to see them. Since I was going to share it on Facebook (and I informed her about that), I reminded her that anyone who visits the page would see her photo. She did not reject participating but seemed uncomfortable. I needed the photo because I had to create a Facebook post for our donor about their successful contribution. It was also hard to receive the consent of other parents for interviewing their children. This is an example of an ethical dilemma that I have faced in the field where I had to choose between wanting to meet the contractual requirements of the donor versus considering Rym's concerns about her privacy and looks. In the following section, I will explain why the current humanitarian principles are insufficient for guiding communications spe-

${ }^{5}$ I am not using the real name here to protect the identity of the girl involved in this incident. 
cialists Then, I will discuss how the feminist ethics of care would have helped me make a moral decision about photographing Rym.

Communications specialists are always susceptible to facing similar dilemmas because their tasks require exposing the stories and bodies of other human beings to the public through photography, filming, interviewing, and writing. Despite that, researchers have continued to ignore questions about the ethics of this job and have instead focused on investigating the implementation of humanitarian ethics on the organizational level (Slim, 1997; Slim, 1997a; Bell and Carens, 2004; SommersFlanagan, 2007). To highlight this gap in the literature, Slim (2015) coins the term "role morality" (p.117) to refer to "a moral posture and particular behaviors that make sense when you are trying to achieve a very specific good, but which do not make sense as a general rule for all areas of life" (Slim, 2015, p.117). Slim (2015) highlights the importance of paying attention to role morality in the humanitarian field by mentioning that: "In practice, humanitarian professionals adopt a role morality much like a doctor, policeman [sic], politician, nurse, soldier, priest or accountant. In their various official roles, members of these professions must act in line with their role responsibilities when they are on duty" (p.117). While the focus on organizational ethics might in part go back to the universal nature of the ethical principles that guide humanitarian action, this paper focuses on role morality.

\section{Humanitarian Ethics}

Seven humanitarian principles have been guiding the humanitarian field since 1965: humanity, impartiality, neutrality, independence, voluntary service, unity, and universality (Pictet, 1979). In addition, the "International Humanitarian Law" and the "Human Rights Law" (Slim, 1997, p.247) also govern the humanitarian field. Applying these principles has always been challenging for humanitarian organizations because "their relevance is sometimes questioned or put to the test by outside events and developments" (Labbé and Daudin, p.2016, p.189). In what follows, I define the four fundamental principles in the humanitarian field, i.e., the principles of humanity, impartiality, neutrality, and independence, and discuss their relevance to humanitarian communications.

\section{Humanity}

The principle of humanity is also one of the goals of humanitarian action "that aims to respect and protect the humanity in everyone" (Slim, 2015, p.45). This principle requires protecting and respecting the physical well-being of vulnerable populations, in addition to their dignity and identity because: 
Our humanity is more than just a body and more than just a mind. It is created by the unity of both and by our association with others. Our life is lived; it does not just exist [...] Each human life has what Ricoeur calls its own "singularity" (Slim, 2015, p.48).

The principle of humanity is the only humanitarian principle that is mentioned in an article that directly addressed communication: the $10^{\text {th }}$ article of the International Committee of the Red Cross (ICRC) and the International Federation of Red Cross and Red Crescent Societies' code of conduct links humanity to dignity and emphasizes the importance of observing this principle in "information, publicity, and advertising activities" (Pictet, 1979, p.5). Humanity aligns with the feminist ethics of care because it calls for approaching the other person as an autonomous entity, with needs, wants, and concerns that are different and independent from oneself. The principle of humanity also calls for respecting that autonomy.

The principle of humanity had guided me to portray Rym in a dignified manner in my photo. However, the way I understood dignity was absolutely different from the way she understood it. I wanted to take a shot depicting her smiling and wearing a neat dress. However, she did not like the idea of being seen and identified by people she did not know or see back. Her dignity entailed protecting her privacy and agency over her body. For Rym, being portrayed in a dignified manner meant having enough time to try several framings and check each without feeling pressured to approve one photo; it meant choosing whether she wanted to smile or look at the camera. The principle of humanity alone does not teach communications specialists that they need to allow enough time and energy to do their job properly, ethically; it does not teach them to listen and understand to other people.

\section{Impartiality}

The principle of impartiality requires the humanitarian worker to assist others regardless of their "nationality, race, religious beliefs, class or political opinions" (Pictet, 1979, p.1). This principle "permits the impartial person to be judgmentalalbeit not gratuitously so, but in line with agreed values," i.e., the value of the need for assistance. I argue that part of the definition of impartiality may be helpful to communications specialists because it calls for approaching all people as equal (to oneself and to one another) and reporting their stories without stereotypical prejudices or biases. Moreover, building on this definition of impartiality, I think this principle aligns with the philosophy behind the ethics of care, which is approaching all human beings as worth caring for and empathizing with. Thus, impartiality intersects with the ethics of care by encouraging the moral agent to respect and care for others based only on need. A caring communications specialist may act upon the 
principle of impartiality in the humanitarian field by, for example, highlighting the stories of the people who are in the most need of support but this principle did not seem relevant to solving the dilemma I faced with Rym.

\section{Neutrality}

The principle of neutrality is, by definition, to "not take sides" in a conflict zone while on a humanitarian mission (Pictet, 1979, p.1). Humanitarian organizations and UN agencies have always challenged the principle of neutrality for two main reasons, according to Slim (1979). The first reason is related to a humans' rights approach to humanitarianism which favors disciplinary procedures towards human rights violators; this approach considers that the principle of neutrality "often imposes an unacceptable silence upon them in the face of grievous violations of human rights" (Slim, 1979, p.348). The other reason is related to field-specific realities linked to funding, political, and demographic particularities. Thus, some organizations consider that the principle of neutrality is "unfeasible in the light of what we now know about the manipulation of relief supplies, and the fact that combatants and civilians are intrinsically mixed in today's civil wars" (Slim, 1979, p.348). In journalism, neutrality provides equal opportunities for opposite sides of a conflict to express their point of view in an article. However, it is unrealistic to expect a humanitarian communications specialist to allow a militant to speak in their story; this is hard to see in real world. So, the principle of neutrality is not relevant to humanitarian communications, and it has been challenged as a journalistic principle in recent years. Neutrality might seem relevant to the logic of feminist ethics of care in its non-exclusionary approach, but the feminist ethics of care is a framework for moral judgment and for taking sides; it's about doing the best thing for the community. So, I do not think that the principle of neutrality syncs with an ethics of care because one cannot care and be neutral at the same time.

\section{Independence}

The principle of independence requires humanitarian organizations to "always maintain their autonomy so that they may be able at all times to act in accordance with Red Cross principles" (Pictet, 1979, p.1). Independence seems the least relevant principle to humanitarian communications because it relates to the organization's structure, sources of funding, and affiliations. But it is worth mentioning that the organization's commitment to the principle of independence can shape its approach to communications, i.e., whether the organization considers communications a tool for meeting donors' requirements or as an autonomous department. Moreover, the organizational commitment to independence or otherwise its politi- 
cal affiliation also influences the quality of the public communications that it produces.

How did these principles help me solve the dilemma of taking a photo for Rym when she was not comfortable having her image seen by many people she does not know? Humanity guided me to portray her in a dignified manner and by seeking her consent and that of her parents. But this principle did not suggest framing my photo in a specific way and dealing with the worried girl. Moreover, the principles of impartiality, neutrality, and independence could not guide me into making the right decision at that point because they did not apply to the situation.

It is hard to have a set of ethical guidelines that can always apply to different and particular situations. Thus, the fact that these universal principles do not address communication activities per $s e^{6}$ leaves a gap in morally practicing humanitarian communication. Moreover, finding ways to improve humanitarian communication continues to be challenging in the absence of academic literature about communication practices in the humanitarian field ${ }^{7}$. In the following section, I highlight the common ground between humanitarian ethics and feminist ethics of care; then, I emphasize the added value of the ethics of care to the existing humanitarian moral principles.

\section{Discussion}

\section{Linking Feminist Ethics of Care and Humanitarian Ethics in Theory}

I understand the common ground between the ethics of care and humanitarian principles as a mutual language and common beliefs. I have recognized the potential rapprochement between both approaches in Slim's (2015) book, where he focuses on "how to be a good humanitarian worker" (p.7). The starting point for realizing this mutuality is understanding the difference between a human rights approach and a humanitarian approach. Slim (2015) explains that the difference between these approaches--often used interchangeably-- is that human rights uphold a punitive approach that pushes its workers to identify human rights violations and

6 The universality of these principles have led to various subjective interpretations and application of these principles, which is a problem that Dijkzeul and Moke (2005) highlight in their paper: "Many of these differences stem from the lack of shared agreement on definitions of the principles at the heart of humanitarian action... Many organizations and their staff lack a thorough understanding of them, or apply them inconsistently" (p. 675).

7 The most salient academic questions in the field of humanitarian communication have focused on the representations that humanitarian organizations produce in their public communication. 
punish the offender. On the other hand, humanitarians are motivated by the principles of humanity and impartiality, so they find themselves ethically obliged to provide aid for anyone in need, even human rights' violators. This reality says a lot about the centrality of the principle of humanity to the work of a humanitarian. Slim (2015) uses the language of care to describe this reality: "Driven by the universal moral value of humanity, humanitarianism hopes for a world in which everyone is motivated by humanitarian impulses to care for and protect each other" (p.10). Caring for other humans is part of being a humanitarian. Moreover, humanitarian principles does not reject emotions, such as sympathy, Slim (2015) mentions that "The ground of ethics in humanitarian action is a profound feeling of compassion and responsibility towards others who are living and suffering in extremis. It is a feeling of identification and sympathy that demands some reasonable and effective action as a response to suffering" (p.26). Slim (2015) also focuses on the importance of approaching beneficiaries as autonomous human beings, which syncs with Gilligan's (1982) definition of particularity and empathy in her discussion of what it means to offer "genuine attention" (Slim, 2015, p.50) during direct interaction with beneficiaries. According to Slim (2015):

Humanitarian attention is not a looking down at people but looking straight at them to connect on equal terms as two people who share the condition of humanity. Proper attention is a meeting not an inspection by one side. In the focused attention of this meeting, a spirit of caring, curiosity, and response needs to be present to ask important questions (p.50).

Slim (2015) presents "responsibility" as the motive behind humanitarian action: "Humanitarian action manifests an emotional concern for other people, and acts from an intuitive sense of responsibility" (p.35). He also emphasizes particularity and response to suffering as part of the humanitarian ethics: "humanitarian practitioners must work face-to-face with affected individuals, and in their best interests, to find practical and often urgent solutions that best meet their needs" (Slim, 2015, p.112).

With its emphasis on approaching others as humans with personal needs and wants, the ethics of care emphasizes humanity and dignity as principles that are intrinsic to its application. Moreover, care, responsibility, sympathy, empathy, humanity, and dignity are terms that are intrinsic to defining humanitarian ethics. This common language between the humanitarian field and feminist ethics is the common ground on which I base my framework. 
What is, then, the added value of the ethics of care when the language of care, empathy, and responsibility is already used for describing humanitarian action and when principles such as humanity and impartiality guide humanitarian action? The added value is recognized when the main difference between both fields is recalled-their differing points of departure or world views. While the humanitarian field departs from the individual rights, the ethics of care starts from responsibility towards the community (Richardson and Fullerton, 2016). Therefore, the ethics of care teaches humanitarian practitioners to consider the impact of their practices on the whole community. This is important because communication representations have always had an impact on the entire community of sufferers (Chouliaraki, 2010). Therefore, communications specialists need to pay attention to the impact of their activities on the community if they want to improve their practices. Moreover, by adopting an ethics of care, the communications specialist would be supporting the whole community rather than individuals. This, consequently, leads to a more positive impact of humanitarian intervention because

The feminist ethics of care also approaches care and responsibility as its core values and starting points. In contrast, the humanitarian field is governed by seven equally important moral principles that are expected to apply to different parts of the world. So, the ethics of care focuses on emotions of care and responsibility more than humanitarian principles do. This, again, would lead to more caring and responsible communications activities that avoid harming the person being involved. Thinking about ways to mitigate the harmful effects of communications activities is very important because the humanitarian domain has always been subject to critiques and continues to commit mistakes against vulnerable people by, for example, objectifying the beneficiaries of assistance (Chouliaraki, 2010; Orgad, 2018).

The ethics of care can always be relevant and useful to any activity that a communications specialist would implement because it is malleable: it's a personal worldview that affects how people see themselves, others, and power. Moreover, the ethics of care acknowledges particularity, so it can be efficient for solving many ethical dilemmas because it guides the agent to decisions that respond to the particular problem. At the same time, the ethics of care does not reject impersonal and universal details. While humanitarian principles are universal, the ethics of care allows for a more balanced approach to ethics that acknowledges "impersonal and purely personal questions" (Blum, 1988, p.474) ${ }^{8}$.

\footnotetext{
${ }^{8}$ According to Blum (1988), "Gilligan holds that there is an appropriate place for impartiali-
} ty, universal principle, and the like within morality and that a final mature morality involves 
Finally, this approach shows communications specialists that they have a duty towards the community with which they interact. It also allows them to see the impact of their behaviors, no matter how simple -- such as smiling, gazing, standing, sitting, asking a question, choosing a word, or dressing in a specific way. Consequently, they recognize that by working for a humanitarian organization and going into the field, they have a duty to be moral agents. By the same token, they realize the moral aspect of each practice they perform and that any of these undertakings involves ethical decision-making.

I believe that the feminist ethics of care would have helped me solve the ethical dilemma I faced when photographing Rym. First, this approach would have allowed me to acknowledge and accept that Rym is an autonomous person with personal concerns and needs. Thus, it would have helped me realize that I cannot apply the general protocols that I usually follow to finish my task. This approach would have encouraged me to spend time with Rym and to try to discover what she wanted and what concerned her about participating in the photo session. If I had been informed by a caring approach, I would have talked to Rym, asked her many questions, told her a few jokes to try to make her laugh and to relax, and allowed her to take some photos of me so she could feel in charge, and help break the ice between us. I would have tried several photo frames and shared the results with her. Using this approach to ethics, I would also have considered taking a wide shot for Rym from behind where she would not be so easy to identify, for example. Moved by respect, I would have set up the photo session as a collaborative work between Rym and me. I would have asked for her thoughts about how to best frame her own photo. Finally, moved by responsibility, I would not leave the field until I was certain that Rym was comfortable with the final image - one we would have selected together.

\section{Feminist Ethics of Care in Action}

How can humanitarian communications specialists apply the feminist ethics of care when on the job? As a starting point, I would like to mention that a sincere implementation of the approach requires a belief in its values and worldview. An individual who wants to practice the feminist ethics of care needs to question the way they see themselves and people around them, notably less privileged or less powerful individuals and communities. They should also think about the prejudices and biases that shape their thoughts and practices. Finally, a person might also need

a complex interaction and dialogue between the concerns of impartiality and those of personal relationship and care" (Blum, 1988, p.474). 
to acknowledge the privileges they enjoy as an individual and a member of a racial, ethnic, gender, or socio-economic group.

The feminist ethics of care is an approach to morality that values particularity. Therefore, it is hard to draw some general rules applicable to all situations out of this framework. However, I would like to provide some tangible examples of how communications specialists may work upon feminist ethics of care. In the following section, I will refer to the beneficiaries of assistance whom communications specialists encounter during field visits as participants.

First, before going to the field, a communications specialist would inform the participants of their visit. Giving notice before a visit is an act of respect to the participants. A caring communications specialist considers the needs and concerns of the participants; so, given the limited psycho-social knowledge that a communications specialist usually has, they should try to avoid doing anything that would trigger negative feelings such as fear or unsafety among participants. Participants usually consider the sites of activities as safe and undisclosed spaces, so seeing a new face without prior notice may trigger some negative feelings. A communications specialist may also consult with the psycho-social specialists who usually follow some protocols for field visits.

A caring communications specialist would make sure that the location of the interview or photo session is proximate, accessible, and comfortable for the participant; the participant should be able to tell their story without the risk of being heard by a third party. Participants should be able to access the location without traveling for a long distance, incurring financial expenses, or interrupting their daily life routine or job. Doing their best to find a convenient location demonstrates a communication specialist's responsibility towards the participant who would often be occupied by household tasks or long hours of low-wage labour.

When a communications specialist arrives at the location, they would start any encounter with people they meet in the field by introducing themselves and their job. If they decided to interview the person or collect quotes from them, they should seek verbal or written informed consent. Implementing an interview with an approach of ethics of care requires thinking about the questions that would be asked. It also involves reflection on one's language, gestures, and body language. When it comes to questions, a communications specialist might focus on more openended questions and less structured interviewing plans to allow the participant to focus on the details and aspects they want to tell. A communications specialist should avoid contributing to stereotypical images or narratives about the vulnerable 
people they interact with. Instead, they should try to be the voice of that community because they have a responsibility towards them by virtue of their job. Moreover, being familiar with cultural cues can prevent a communications specialist from making mistakes that show disrespect or ambivalence, which might harm the participant and break the trust.

Finally, a communications specialist should continue to act upon the consent terms after returning to their offices. So, if a participant has refused to share their story on social media, the communications specialist should commit to that. Also, when writing their story, a caring communications specialist should spare enough time to reflect on the language they use; this is important because acting upon responsibility towards the person and the community they represent requires avoiding any possible harm resulting from the article or photo they are circulating.

\section{Conclusion}

Research about ethics in the humanitarian field rarely focuses on role morality, and research on communication in this field rarely focuses on practices. This paper was an attempt to fill the gap in academic literature at the intersection of humanitarian ethics and humanitarian communication. It suggests adopting a feminist ethics of care as a moral framework to better guide the decisions of humanitarian communication specialists, particularly when they are on field visits. In this paper, I have argued that this feminist approach, even though it comes from a different world view than that of a humanitarian one, can speak the same language as humanitarians. I invested in the common ground between humanitarian ethics and feminist ethics of care to show that the latter can be efficiently used in the former. Moreover, I argued that the feminist ethics of care can bring an added value to practicing humanitarianism, particularly in the role of a communications specialist. This paper acknowledges that acting upon the ethics of care is not easy; it requires a shift in the person's worldview and an understanding of their responsibility towards the community that their job allows them to access. To achieve that, it might be useful to start the process by questioning one's biases, prejudices, and privileges. Moreover, training oneself on practicing emotions of sympathy, empathy, and care might be a good start to adopt feminist ethics of care approach while on the job of a humanitarian communications specialist. 


\section{References}

Bell, D. A. and Carens, J. H. (2004). The Ethical Dilemmas of International Human Rights and Humanitarian NGOs: Reflections on a Dialogue Between Practitioners and Theorists. Human Rights Quarterly, 26(2), 300-329.

Blum, L. (1988). Gilligan and Kohlberg: Implications for Moral Theory. Ethics, 98(3), 472-491. Retrieved July 9, 2021, from http://www.jstor.org/stable/2380962.

Caswell, M., \& Cifor, M. (2016). From Human Rights to Feminist Ethics: Radical Empathy in the Archives. Archivaria, 81, 23-.

Chouliaraki, L. (2010). Post-humanitarianism: Humanitarian Communication Beyond a Politics of Pity. International Journal of Cultural Studies, 13(2), 107-126. https://doi.org/10.1177/1367877909356720.

Clement, G. (2013). Feminist Ethics. In H. LaFollette (Ed.), The International Encyclopedia of Ethics (pp. 1925-1938). Blackwell Publishing Ltd. https://doi.org/10.1002/9781444367072.wbiee108.

Dijkzeul, D., \& Moke, M. (2005). Public Communication Strategies of International Humanitarian Organizations. International Review of the Red Cross, 87(860), 673691. doi:10.1017/S1816383100184504.

Gilligan, C. (1982). In a Different Voice [electronic resource]: Psychological Theory and Women's Development. Harvard University Press.

Held, V. (2006). The Ethics of Care [electronic resource]: Personal, Political, and Global. Oxford University Press.

Kohlberg, L. (1981). Essays on Moral Development [1st ed.]. Harper \& Row.

Labbé, J., \& Daudin, P. (2015). Applying the Humanitarian Principles: Reflecting on the Experience of the International Committee of the Red Cross. International Review of the Red Cross, 97(897-898), 183-210. https://doi.org/10.1017/s1816383115000715.

Lindemann, H. (2019). An Invitation to Feminist Ethics / [electronic resource] (Second edition.). Oxford University Press.

Orgad, S. (2018). Communication. In T. Allen, A. Macdonald, \& H. Radice (Eds.), Humanitarianism. A Dictionary of Concepts (pp. 68-80). Abingdon: Routledge.

Ong, J. C. (2019). Toward an Ordinary Ethics of Mediated Humanitarianism: An Agenda for Ethnography. International Journal of Cultural Studies, 22(4), 481-498. https://doi.org/10.1177/1367877919830095. 
Pictet, J. (1979, January 01). The Fundamental Principles of the Red Cross: Commentary. Retrieved February 26, 2021, from https://www.icrc.org/en/doc/resources/documents/misc/fundamentalprinciples-commentary010179.htm\#: :text=Its\%20purpose $\% 20$ is $\% 20$ to\%20protect,lasting\%20peace \%20amongst $\% 20$ all $\% 20$ peoples.\&text=It $\% 20$ makes $\% 20$ no $\% 20$ discrimination $\%$ 20as,beliefs \%2C\%20class\%20or\%20political\%20opinions.

Quinn, M, J. (2014). Introduction to Ethics. In Downloaded Ethics for the Information Age (6th ed., pp. 49-104). Essay, Addison-Wesley.

Quintanilla, J., Hardman, J., Abud, M., Campbell, A., \& Ensor, D. (2014, January). Reporting on Humanitarian Crises: A Manual for Trainers \& Journalists and an Introduction for Humanitarian Workers. Internews. Retrieved February 17, 2021, from https://www.internews.org/sites/default/files/201806/IN140220 HumanitarianReportingHANDOUTS WEB.pdf.

Richardson, G., \& Fullerton, R. S. (2016). Media's Role in the Rob Ford "Crack-Tape" Scandal. In Mandell, H., \& Chen, G. M. (Eds.), Scandal in a Digital Age (pp. 145157). Palgrave Macmillan US. https://doi.org/10.1057/978-1-137-59545-4_12

Slim, H. (1997). Relief Agencies and Moral Standing in War: Principles of Humanity, Neutrality, Impartiality and Solidarity. Development in Practice, 7(4), 342-352. Retrieved February 16, 2021, from http://www.jstor.org/stable/4029000.

Slim, H. (2015). Humanitarian Ethics: A Guide to the Morality of Aid in War and Disaster. Oxford University Press.

Sommers-Flanagan, R. (2007). Ethical Considerations in Crisis and Humanitarian Interventions. Ethics \& Behavior, 17(2), 187-202. https://doi.org/10.1080/10508420701378123.

UNHCR. (n.d.). Emergency Handbook. UNHCR. https://emergency.unhcr.org/entry/50478/communitybased-protection.

Wall, S. (2008). Easier Said Than Done: Writing an Autoethnography. International Journal of Qualitative Methods, 7(1), 38-53. https://doi.org/10.1177/160940690800700103. 